\title{
Connecting the Post-Training Task and Contextual Performance with the Essentials of Training Program and Characteristics of Trainees
}

\author{
Hamid Hassan ${ }^{1,2}$, Sarosh Asad $^{1} \&$ Yasuo Hoshino ${ }^{3}$ \\ ${ }^{1}$ FAST School of Management, National University of Computer and Emerging Sciences, Lahore Pakistan \\ ${ }^{2}$ Institute of International Affairs, Aichi University, Nagoya, Japan \\ ${ }^{3}$ Graduate School of Accounting, Aichi University, Japan \\ Correspondence: Hamid Hassan, School of Management, National University of Computer and Emerging \\ Sciences, Lahore, Pakistan. E-mail: hamid.hassan@nu.edu.pk
}

Received: December 22, 2015

Accepted: February 4, 2016

Online Published: March 15, 2016

doi:10.5539/ijbm.v11n4p48

URL: http://dx.doi.org/10.5539/ijbm.v11n4p48

\begin{abstract}
A successful training program leads to improved performance; however, lack of evaluation on what makes a training program effective yet puzzles managers. It is imperative to know which elements of a training program and individual characteristics of a trainee impact the employees' performance in order to realize prolific returns from this expensive investment. This study reviews three training elements namely the duration, methodology and area and two individual characteristics: education level and experience of a trainee to assess their impact on task and contextual dimensions of performance. Results support a positive impact of duration and on the job training methodology for resultant performance of employees with better level of education. Experience of trainees have a significant effect on contextual performance while no effect on task performance of employees.
\end{abstract}

Keywords: Training duration, on the job training, of the job training, education, task performance, contextual performance

\section{Introduction}

Several past studies validate that training can positively impact the employees' performance (Aguinis \& Kraiger, 2009; Aragon-Sanchez et al., 2003; Arthur et al., 2003; Georgiadis \& Pitelis, 2014). However, defining the important elements of training program and characteristics of trainees that matter for the resultant performance of those being trained is yet to be fully explored (Lee, 2015). This study reaffirms the impact of training on performance by focusing on the objective of identifying those elements of a training program and characteristics of a trainee which significantly impact the performance of an employee.

Businesses of the twenty first century are increasingly becoming cognizant of the impact of rapid globalization, unprecedented technological growth, invariably vying markets and multi-skilled workforce to attain sustained competitive advantage. It has become critical to differentiate and enhance employees' skills and knowledge in order to increase productivity (Alliger et al., 1998; J van Zolingen et al., 2000; Aguinis \& Kraiger, 2009). Therefore, survival of the businesses in today's competitive markets necessitates that antiquated business practices, which no longer are a source of competitive advantage, are discarded and in lieu replaced with practices that enhance productivity. This will allow the business to prosper which is only possible with continued investment in training of employees (Morikawa, 2015). Not surprisingly, one of the several changes that define the new business dynamics in the present century is the extensive prevalence of employee training (Hughey \& Mussneg, 1997).

Employee training is part of the human element which has been lately much emphasized as one of the internal resources to provide competitive advantage (Alliger et al., 1998; Aragon-Sanchez et al., 2003). This human element is needed to enhance bottom line, increase efficiency and to enable employees to learn and apply skills proficiently (Hughey \& Mussneg, 1997). Krebs et al. (2011) and Morikawa (2015) explains that human capital, comprised of training and schooling, is essential for long-term growth of the economy by enhancing the productivity of employees and firms. Companies, nowadays, are extensively providing training to improve the skills of their employees in order to attain a competitive edge over competitors and strategic value of training has gained considerable interest in the literature since last few years (Aragon-Sanchez et al., 2003). To maximize the 
payoffs from an often substantial training investment, organization must effectively synchronize the objectives of the training program with the strategic objectives of the company (Hughey \& Mussneg, 1997). The need for training is more pronounced than ever today which implies that continual investment in training is necessary to improve the quality of employees and to increase productivity (J Van Zolingen et al., 2000).

Despite the importance of training programs as enablers for attaining strategic objectives of an organization, enigma about the how investment in training may impact an organizational performance continues to puzzle managers (Aragon-Sanchez et al., 2003). Wexley et al. (1991) and Arthur et al. (2003) highlight that relation between training and performance is defined by uncertainty due to lack of evaluation of training programs by companies administrating them. Organizations fail to realize the guerdon from the administered training programs because of either unaware or unable to measure the impact of training on performance (Aragon-Sanchez et al., 2003; Kraiger et al., 2004; Krebs et al., 2011). The desired long-term impact of training is to improve individual \& organizational performance and, ultimately, to contribute to the achievement of goals and increase in productivity (Georgiadis \& Pitelis, 2014).

This study explain the role of elements of training i.e., Training duration, training methodology and training area, and two characteristics of trainees i.e., education level and experience of trainees to explore the link between training and resultant performance measured in both task and contextual perspectives.

The remainder of the paper is organized into five additional sections. Section two, following the introduction part, discusses the past literature on training and two types of performance i.e. task and contextual. Section three presents the hypotheses of the study and the conceptual model.Section four explains the methodology and data sources used to test the model; determining the impact of elements of training program and trainees' individual characteristics on performance. The last two sections highlight the results, discussion and conclusion of study.

\section{Literature Review}

According to Hughey and Mussneg (1997), training entails "personal involvement, commitment and experiential gains" with an aim to "provide employees with proficiency in execution of given tasks". Emphasis on training programs was placed during the 1980 's which aimed at maximizing variety of skills as well as to develop new skills and competencies of employees to compete in a business environment (Georgiadis \& Pitelis, 2014; Krebs et al., 2011). Several demands have instigated need for individual and organizational development and training as one of the most pervasive methods to attain this objective (Wexley, 1984; Wexley et al., 1991; Madera et al., 2011). Trainings can be regarded as a means of enhancing and improving human capital as an output (Alliger et al., 1998; Salas et al., 2009; Barrett et al, 2011).

Two eminent methodologies to provide training to the employees include on-the-job training (OJT) and off-the-job training (OFT). OJT differs from its traditional counterpart OFT in that it is a one-to-one instruction that occurs at the place where job itself is actually performed (J Van Zolingen et al., 2000; Salas et al., 2009). Matsuo (2014) proposed the "70/20/10 model" according to which $70 \%$ of the learning of an individual takes place through on-the-job experience clearly headlining the criticality of training and more specifically OJT methodology. OJT has swiftly overshadowed the use of traditional OFT methodology because the new business realities demand job specific and company specific approach to management training (Alliger et al., 1998; J Van Zolingen et al., 2000; Barrett \& O'Connell, 2001; Mafi, 2001). Other reasons for this change are obvious advantages of OJT which include a strong link between training and practice, effective learning of skills on the job, cost-effectiveness and no transfer problem because training is given at the site where the employee would work (J Van Zolingen et al., 2000; Artis \& Harris, 2007). OJT is specifically helpful in terms of improving the contextual performance as trainees learn how on the job cooperation with others can mutually enhance outputs (Lechner, 1999; Matsuo, 2014). OFT, often classroom based, has been criticized for neglecting the important element of learning i.e. work experience as well as for often not producing positive results (Lechner, 1999; Mafi, 2001). However, task specific expertise and new skills need focused approach that OFT provide better than OJT where focus is divided into job requirements and learning (Barron et al., 1999; Lechner, 1999). Cron et al. (2005) reports that young people tend to prefer OJT when they began their contract of training. This preference is shifted towards OFT during the first year of employment when understanding about how OFT can aid in eliminating deficiencies in the workplace is matured.

Another important element of a training program is the training area i.e., focus of training program on job specific skills or general skills. Loewenstein and Spletzer (1999) explain that general training is investment in the general human capital that raises a worker's potential of productivity at other firms to the same extent as at the employer that provides the training. Similarly, job specific training at a company is defined as an investment in specific human capital that increases the workers potential of productivity specifically at the employer that 
provides the training (Alliger et al., 1998; Arthur et al., 2003). Employers may prefer giving job specific training over general training because the benefit can be lost, in case of latter, if employees with general training leave the firm which trained them. Job specific training decreases this uncertainty associated with the investment on human capital (Krebs et al., 2011). Barron et al. (1999) explain that an employee endures the full expense of general training and receives lower initial wages which become higher in the future. In contrast, the costs and returns are shared by worker and the firm in case of specific training (Loewenstein \& Spletzer, 1999; Barrett et al., 2011).

Apart from the elements of training program, trainees' individual characteristics also contribute to the effectiveness of a training program (Mohammed et al., 2002). According to Warr and Bunce (1995), educational qualifications are positively correlated with learning as it indicates an individual's' personal previous experience and motivation for learning. Experience of an individual also influence learning but it remains unclear whether high experience in a particular job would be able to augment performance of an individual undertaking the training for the same job (Mathieu et al., 1992; Murthy et al., 2008).

Providing training to employees is an expensive investment which necessitates mangers to not just know whether training program has worked but also how investment on training can be optimized by better resultant performance of trainees (Mathieu et al., 1992). The concept of performance is multidimensional and two prominent dimensions of performance are task and contextual performance (Ibrahim, 2004). Katz and Ziderman (1990) explain task performance as the effectiveness of incumbents to perform technical core either by implementing the process, or by providing materials or services. In contrast, contextual performance consists of those non-job-specific behaviors that enable a good environment for task performance to occur by shaping the social and psychological contexts and consequently contributing to organization's effectiveness (Katz \& Ziderman, 1990; Kessler \& Lulfesmann, 2006). The need to antithesize between the two performance dimensions arise from the fact that contextual performance's role as contributor of organizational performance has been ignored in the literature (Conway, 1999; Loewenstein \& Spletzer, 1999). This study attempts to determine the effectiveness of elements of training program and trainees' characteristics on both task as well as contextual performance of trainees.

\section{Hypotheses and Model}

This research was undertaken to empirically address the impact of different elements of training program and trainee's characteristics on individual's task and contextual performance. Three facets of a training program are considered that can potentially impact the resultant performance of an individual. These include, training's duration, methodology and area. Two important characteristics of trainees are proposed to have an impact on the performance outcomes of trainees after the training program which include level of education and experience of participants. Relevant hypotheses regarding the elements of training program and characteristics of trainees are explained below.

The first factor, under analysis, is the training's duration which impacts the performance. Long duration being likely to enhance performance more by covering a large number of aspects in detail and in a more appropriate way to develop skills and competencies, consequently improving the output of employees (Attia et al., 2005; Sharma, 2014; Abugre \& Adebola, 2015). Thus it is reasonable to expect as hypothesis H1.

H1: Longer Duration of training program has a positive impact on an employee's performance following the training program (task and contextual).

The two eminent methodologies for providing training to employees are OFT and OJT. OFT is a traditional approach of training programs vis-à-vis OJT that is gradually becoming conspicuous due to advantages of strong link between training and practice, flexibility, cost effectiveness and no transfer problems ( $\mathrm{J}$ Van Zolingen et al., 2000). However, OFT method continues to be used by managers with expectation of the benefit of focused learning that can be helpful in task performance (Wexley, 1984; Wexley et al., 1991; Murthy et al., 2008). It is therefore hypothesized as $\mathrm{H} 2$ (a) and $\mathrm{H} 2$ (b).

H2 (a): On-the-job training has a greater positive impact on an employee's contextual performance following the training program, as compared to task performance.

H2 (b): Off-the-job training has a greater positive impact on an employee's task performance following the training program, as compared to contextual performance.

Organizations provide job specific and general training to employees. Katz and Ziderman (1990) explain that employers prefer giving job specific training over general training because employees can carry the latter when they switch job. Moreover, employers tend to prefer job specific training as it decreases uncertainty associated 
with their investment on their human capital (Katz \& Ziderman, 1990; Kessler \& Lulfesmann, 2006; Mohammed et al., 2002; Krebs et al., 2015). However, general training also gets considerable attention from employers as it helps in developing the underlying basic skills and professional expertise that can improves the overall performance of the organization. Thus, it is hypothesized as $\mathrm{H} 3$ (a) and $\mathrm{H} 3$ (b).

H3 (a): Job specific training has a greater positive impact on an employee's task performance following the training program, as compared to contextual performance.

H3 (b): General training has a greater positive impact on an employee's contextual performance following the training program, as compared to task performance.

Apart from the training program designed by the employer, employee characteristics such as education level and experience were also analyzed to assess their effect on employee's performance. While training programs are designed with consideration of the required education level of trainees, within the given pool of trainees, those with comparatively better level of education are expected to be better recipients of learning process (Mohammed et al., 2002). Other things being equal, a higher level of education indicates the past experience of learning and improvement. Employees with better level of education are expected to show more interest in training and thereby have an increased participation and tendency to learn (Morikawa, 2015). On the other hand, employees with comparatively lower level of education may need extra effort while learning process. Thus, it is hypothesized below as $\mathrm{H} 4$.

H4: Higher level education has a positive impact on an employee's performance following the training program (task and contextual).

Employee's experience is another employee characteristic of interest. Experience can make it easy to learn new skills (Madera et al., 2011). Similarly, past experience in the relevant area reflects it's broader understanding and thereby expedites the learning and improvement in resultant performance. On the other hand, increase in experience and age may bring more resistance to change. Therefore, previous experience may impede employees to adjust with the modified work place requirements (Murthy et al., 2008). It will be interesting to see the effect of number of years of experience on the resultant performance of employees after the training program. It is therefore hypothesized:

H5: Greater experience has a positive impact on an employee's performance following the training program (task and contextual).

This study also endeavored to assess the impact of employees' experience level and education on performance in association with the duration of the training programs. When an employee will receive longer duration training, it is likely that effect of experience and education can be further enhanced on the resultant performance following the training program. Employee with higher level of education will be more motivated to undergo training and will be able to understand and implement the training contents more effectively on the job. Employee's previous experience is also proposed to play a great role in the learning program as training duration increases. It is therefore hypothesized as $\mathrm{H} 6$ and $\mathrm{H} 7$ below.

H6: Longer duration of training with higher level of education has a positive impact on an employee's performance following the training program (task and contextual).

H7: Longer duration of training with better experience has a positive impact on an employee's performance following the training program (task and contextual)

Figure1 illustrates the conceptual framework of the study based on hypotheses developed in the earlier part. 


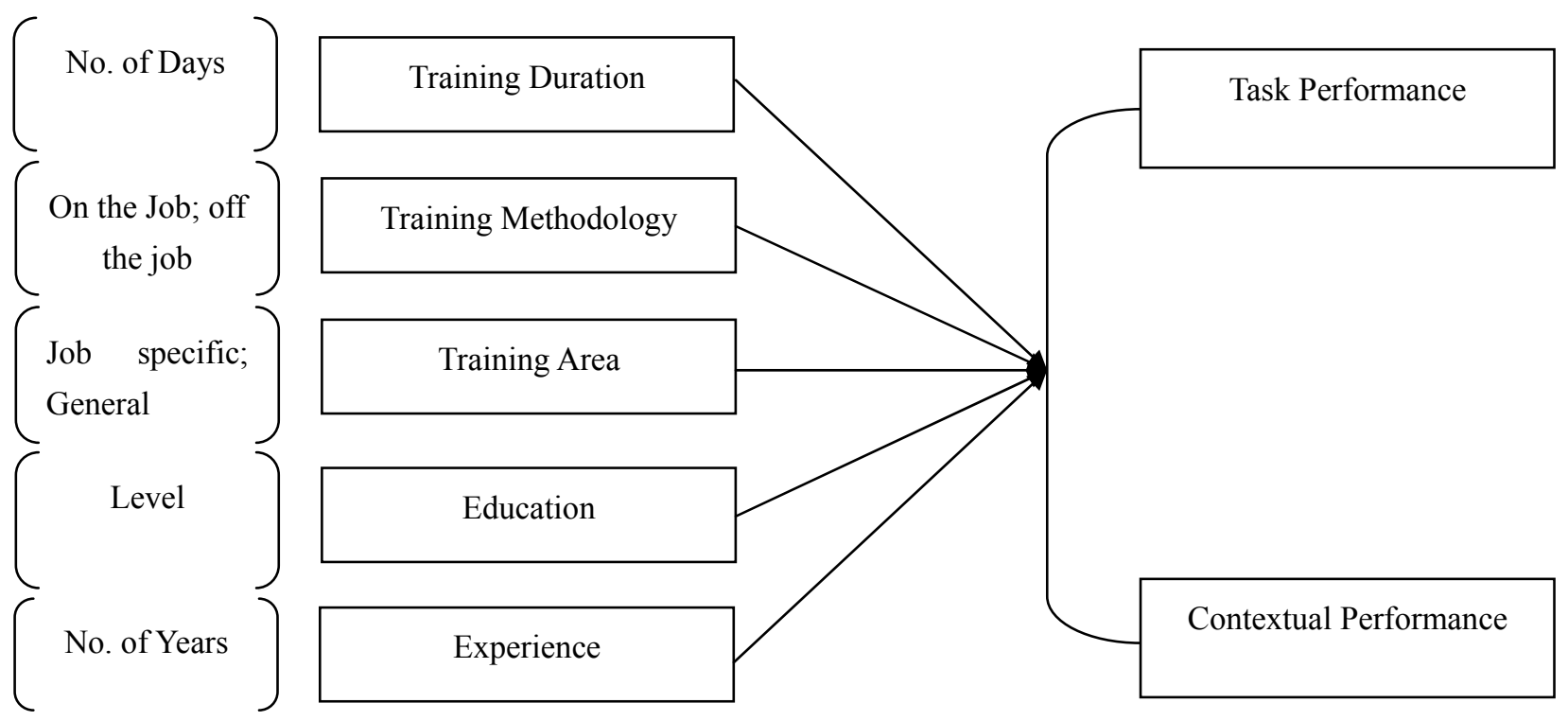

Figure 1. Conceptual framework

\section{Methodology}

\subsection{Data Source}

The research employed individual level data extracted from participants belonging to the banking sector of Pakistan to analyze the impact of training and trainees' characteristics on task and contextual performance. The data was obtained about employees' task and contextual performance, training determinants and trainees' characteristics selected in the study. By analyzing the impact of each of the training determinants and trainees' characteristics on employees' task and contextual performance, this study attempts to explore the most important variables that can play a significant role in improving the employee's performance followed by the training program. The study involved two type of performance measures i.e., task and contextual, as dependent variables. Hundred participants belonging to various banks namely Bank Alfalah, Askari Bank, Muslim Commercial Bank, Jahangir Siddiqui Bank and Habib Bank, located in a metropolitan city of Pakistan, participated in the study. The data about employees' performance was collected from both employees as well as by the supervisor of employees' to counter the effect of self-serving behavior on the part of employees about the performance improvement followed by training program.

\subsection{Assessment of Dependent Variable}

The study involved job performance as dependent variable. Job performance has been further divided into task performance and contextual performance in order to assess the impact of training on both dimensions of an employee's performance. Task performance has been captured by asking questions from the employee regarding task related level of effort, commitment and achievements while contextual performance has been measured in terms of questions focusing on pro-social behavior and intention to help coworkers.

Separate questionnaires were designed for employee and the supervisor to assess the job performance before and after the completion of training program. Total twelve statements were presented to both employees and their supervisors to represent their strength of agreeableness and disagreeableness against each statement on a 5-point response scale ranging from 1 (Strongly disagree) to 5 (strongly agree). The first six items on the questionnaire inquired about task performance while the rest assessed the contextual performance. The difference of performance score before and after training was computed for each question to assess the impact of training on the resultant task and contextual performance of employees.

\subsection{Assessment of Independent Variable}

The employees, in contrast to supervisors, filled an additional section which aimed at collecting data about independent variables i.e. duration, methodology and area of the attended training program, their education level and number of years of experience they hold. Information about duration, methodology and area of training was counter checked from the official record of the company. Among dependent variables, training methodology indicates the form of training undertaken by the employees which includes on-the-job (OJT) and 
off-the-job-training (OFT) methodologies. It was denoted with a dummy of taking value 0 for OJT and 1 for OFT. Training duration explains the length of training program and has been measured in number of days. Another variable regarding the training program is the training area which refers to the type of training an employee has attended. It was again measured with a dummy of taking value 0 for job specific training and 1 for general skills training. Education and experience of employees were assessed in terms of number of years. Experience under consideration was the total banking experience of an employee i.e., total number of years the employee has been working in the banking sector.

\section{Empirical Analyses}

\subsection{Descriptive Statistics and Univariate Analyses}

The descriptive statistics for the independent variables are presented in Table 1 (A) \& (B). Table 1(A) presents frequencies for qualitative independent variables $\mathrm{i}$-e education, methodology and training area whereas Table (B) presents descriptive statistics for quantitative independent variables i.e. training duration and employees' experience.

Table 1(A). Frequency of qualitative independent variables

\begin{tabular}{lll}
\hline Variables/Categories & Percentage & Observation \\
\hline Education: Bachelors or less & 28 & 100 \\
Masters or more & 72 & 100 \\
Methodology: On-job training & 73 & \\
Off-job training & 27 & 100 \\
Training Area: Job specific & 88 & \\
General & 12 & \\
\hline
\end{tabular}

Table 1(B). Descriptive statistics for quantitative independent variables

\begin{tabular}{lllll}
\hline Variables/Categories & Mean & Median & Std. Deviation & Observations \\
\hline Training Duration & 14.7 & 14.00 & 13.34 & 100 \\
Experience & 3.25 & 2.00 & 2.95 & 100 \\
\hline
\end{tabular}

It can be generalized that out of the total sample, majority of the individuals possessed at least master's degree or more in the banks under study. Similarly, majority of the targeted sample attended training program which primarily enhanced job specific skills. It can be noted that most of the employers who invest in training for their employees focus majorly on enhancing job specific skills of an employee and thereby focusing more on task performance of an employee.

Out of the total sample of 100 employees, the mean training duration is 14.7 days with the standard deviation of 13.34. The average experience of the employee is 3.25 years with a standard deviation of 2.95 years between the sample values. Normality of the data was verified by Kolmogorov-Smirnov Test which revealed that the sample met the requirement for normality.

Table 2. Univariate analysis

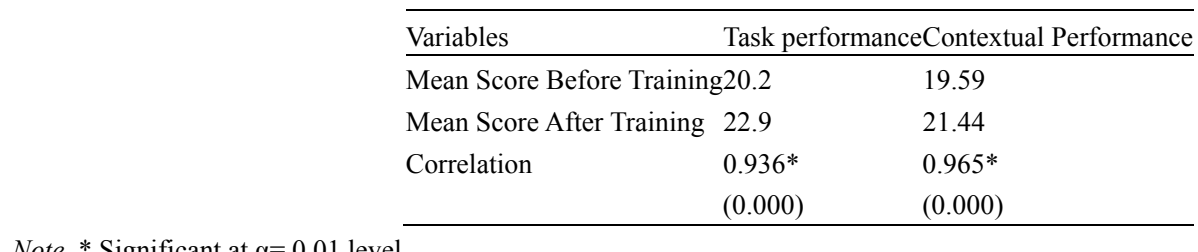

Table 2 presents the results of univariate analyses to see the difference of means before and after the task and contextual performance of employees. 
Table 3. Correlation analysis

\begin{tabular}{lllllllll}
\hline Variables & Label & VIF & Tolerance & Dur & Edu & Exp & Area & Mtg \\
\hline Duration & Dur & 1.286 & 0.778 & 1 & & & & \\
Education & & & &. & & & & \\
& Edu & 1.032 & 0.969 & 0.175 & 1 & & & \\
Experience & Exp & \multirow{2}{*}{1.030} & 0.971 & -0.101 & 0.113 & 1 & & \\
& & & & $(0.31)$ & $(0.26)$ &. & & \\
Area & Area & \multirow{2}{*}{1.050} & 0.953 & 0.165 & -0.025 & -0.010 & 1 & \\
& & & & $(0.10)$ & $(0.80)$ & $(0.91)$ &. & \\
Methodology & Mtg & 1.253 & 0.978 & 0.100 & 0.072 & -0.017 & 0.191 & 1 \\
& & & & $(0.046)$ & $(0.475)$ & $(0.867)$ & $(0.57)$ &. \\
\hline
\end{tabular}

Table 3 shows the result of Pearson correlation matrix, variance inflation factor and tolerance level between the independent to variables. Only correlation between training duration and methodology is significant. However, value of variance inflation factor (VIF) is well below the allowable limit of 2. Similarly, values of tolerance level allows the inclusion of independent variables in the regression.

\subsection{Regression Results and Discussion}

Table 4. Regression analysis for dependent variable: task performance

\begin{tabular}{|c|c|c|c|c|}
\hline Label & Variables & Model 1 & Model 2 & Model 3 \\
\hline \multirow[t]{2}{*}{ Constant } & & $0.805^{* *}$ & $0.584 * * *$ & $0.805^{* *}$ \\
\hline & & $(0.039)$ & $(0.002)$ & $(0.050)$ \\
\hline \multirow[t]{2}{*}{ Dur } & Training Duration & $0.077 * * *$ & 0.007 & $0.077 * * *$ \\
\hline & & $(0.000)$ & $(0.009)$ & $(0.002)$ \\
\hline \multirow[t]{2}{*}{ Methdlgy } & Training Methodology & $0.367 * * *$ & $0.412 * * *$ & $0.367 * * *$ \\
\hline & & $(0.000)$ & $(0.000)$ & $(0.021)$ \\
\hline \multirow[t]{2}{*}{ Area } & Training area & 0.032 & 0.033 & 0.032 \\
\hline & & $(0.554)$ & $(0.543)$ & $(0.554)$ \\
\hline \multirow[t]{2}{*}{ Edu } & Education & $0.811^{* * *}$ & 0.091 & $0.811^{* * *}$ \\
\hline & & $(0.000)$ & $(0.113)$ & $(0.001)$ \\
\hline \multirow[t]{2}{*}{ Exp } & Experience & -0.049 & -0.035 & -0.049 \\
\hline & & $(0.354)$ & $(0.519)$ & $(-0.932)$ \\
\hline \multirow[t]{2}{*}{ Dur x Edu } & Training duration*education & & $0.042 * * *$ & \\
\hline & & & $(0.000)$ & \\
\hline \multirow[t]{2}{*}{ Dur x Exp } & Training duration*experience & & & -0.045 \\
\hline & & & & $(-0.681)$ \\
\hline R-squared & & 0.741 & 0.726 & 0.741 \\
\hline F-Value & & $91.31^{* * *}$ & $128.22 * * *$ & $91.31 * * *$ \\
\hline $\mathrm{N}$ & & 100 & 100 & 100 \\
\hline
\end{tabular}

** Significant at 0.05 level, ${ }^{* * *}$ Significant at 0.01 level. 
Table 5. Regression Analysis for dependent variable: Contextual performance

\begin{tabular}{|c|c|c|c|c|}
\hline Variables & Label & Model 1 & Model 2 & Model 3 \\
\hline \multirow[t]{2}{*}{ Constant } & & 0.466 & $.564 * *$ & 0.248 \\
\hline & & $(0.294)$ & $(0.02)$ & $(0.59)$ \\
\hline \multirow[t]{2}{*}{ Dur } & Training Duration & $0.037 * * *$ & -0.002 & 0.126 \\
\hline & & $(0.000)$ & $(0.445)$ & $(1.17)$ \\
\hline \multirow[t]{2}{*}{ Methdlgy } & Training Methodology & $0.635 * * *$ & $0.519 * *$ & $0.691 * * *$ \\
\hline & & $(0.009)$ & $(0.049)$ & $(0.005)$ \\
\hline \multirow[t]{2}{*}{ Area } & Training area & -0.142 & -0.145 & -0.126 \\
\hline & & $(0.09)$ & $(0.08)$ & $(0.11)$ \\
\hline \multirow[t]{2}{*}{ Edu } & Education & $0.089 * * *$ & 0.146 & $0.694 * * *$ \\
\hline & & $(0.014)$ & $(0.104)$ & $(0.007)$ \\
\hline \multirow[t]{2}{*}{ Exp } & Experience & $0.526^{* *}$ & $0.099 * *$ & -0.036 \\
\hline & & $(0.051)$ & $(0.048)$ & $(0.041)$ \\
\hline \multirow[t]{2}{*}{ Dur x Edu } & Training duration*education & & $0.022 * * *$ & \\
\hline & & & $(0.000)$ & \\
\hline \multirow[t]{2}{*}{ Dur x Exp } & Training duration*experience & & & 0.009 \\
\hline & & & & $(0.052)$ \\
\hline R-squared & & .370 & .350 & .409 \\
\hline F-Value & & $13.9 * * *$ & $17.29 * * *$ & $22.16 * * *$ \\
\hline $\mathrm{N}$ & & 100 & 100 & 100 \\
\hline
\end{tabular}

** Significant at 0.05 level, *** Significant at 0.01 level.

Six different regressions were used to see the impact of independent variables on task performance and contextual performance. Model 1, 2 and 3 presented in Table 4 show the results of regression with task performance as dependents variable. Model 4, 5 and 6 of Table 5 explain the results of regression analyses with contextual performance as dependent variable. Better value of $\mathrm{R}^{2}$ in Table 4 (i.e., for task performance) vis-a-vis in Table 5 (i. e., for contextual performance) is in line with the fact that most of the trainings in the selected sample were targeting the task performance as a norm in the industry.

Model 1 in Table 4 shows the impact of five independent variables on the task performance of employees. Results support H1 (a) that longer duration can reveal better output in terms of task performance of employees after the training. Similarly, OJT turned out to be preferable choice for the task performance after the training exercise. These findings are in line with the increasing use of OJT and resultant benefits emphasized in contemporary literature (J Van Zolingenet al., 2000; Artis\& Harris, 2007; Laberge et al., 2012; Matsuo, 2014). Training area could not get significant results however, it shows the positive signs in line with the preposition of H3(a) which implied that job specific trainings positively affects the task performance of employees after the training. As hypothesized in $\mathrm{H} 4$ a better level of education shows a significant improvement in task performance. The results are in compliance with the findings of Mohammed et al. (2002) and Morikawa (2015) that a higher level of education is helpful in learning and implication of new skills. The preposition of better task performance with a higher level of employees' relevant experience could not get supported. This might be explainable with the fact that greater experienced coupled with age make the learning process slow with more resistance to change. This is in line with the explanation of Murthy et al. (2008) that elaborates the effect of trainees experience and age on the performance of training program. Model 2 includes the interaction of training duration and level of education to investigate the combine effect of better level of education with longer duration of training on the resultant task performance. While results show significant signs, the coefficient value is less than the coefficients of education and training duration measured independently in Model 1. Hence, H6 could not get supported. Model 3 in Table 4 include the interaction of experience and duration of training to test the effect on resultant task performance after the training. The coefficient is insignificant with a negative sign rejecting the hypothesis H6.

Model 4 in Table 5 presents the effect of five independent variables on the contextual performance of employees after the training exercise. Training duration shows positive significant results in line with Hypothesis H1 (b). OJT methodology shows positive significant results for the contextual performance, similar to task performance results in Model 1 of Table 4. This implies that OJT can have a better positive impact on both task and contextual performance vis-a-vis traditional OFT methodology. Results are in line with the findings of Laberge et al.(2012) 
and Matsuo (2014) on the benefits of OJT for better leering, involvement and resultant performance. Training area shows insignificant but negative signs. The results are explainable with the majority of sample having job specific training rather than general training. Consequently, job specific trainings may not have a significant effect on the contextual performance. Results show that level of education can positively affect the contextual performance as hypothesized in H4. This is in line with the findings of positive effect of education on the task performance explained in Model 1 of Table 4. However, unlike task performance, experience shows a positive impact on the resultant contextual performance. This interesting finding is explainable with the fact that increase in experience and age make employees realize the importance of job context thereby improving the contextual performance after the training exercise regardless of the training nature (Madera et al., 2011). Model 5 include interaction of education with the duration of training to see the combine effect on the contextual performance. The results show positive significant coefficient, however coefficient value is less than the individual coefficients of these variables obtained in Model 4 as well as in Model 5. It is therefore implied that while better level of education and longer duration of training positively affect the contextual performance after the training, these effects are independent of each other. Model 6 includes the interaction of experience with the duration of training. While experience shows significant effect on contextual performance, its interaction with duration of training could not get significant results. This implies that experience and duration of training both have positive effect on contextual performance, but are independent of each other.

\section{Conclusion and Limitations}

This research adds to the anthology of training and performance literature by exploring the role of elements of training and characteristics of trainees in explaining the link between training and resultant performance measured in both task and contextual perspectives. Longer duration of training not only provide greater chances to increase the ability of an employee related to the particular field but also enables an individual to realize the context of job and hence increase the contextual performance. OJT methodology shows more favorable impact on both task and contextual performance as compared to OFT. This is explainable with the descriptive characteristics of sample that shows a strong link between methodology of training OJT and training duration, explained in Table 3 (i.e., OJTs unusually extend on greater number of days as compared to OFTs). This can be one the reason of success of OJT that they are provided for longer period of time and allows employees with greater opportunities to learn and assimilate new things as compared to OFTs. The third element under scrutiny i.e. training area could not show the expected results.

Individual characteristic of trainees such as education level was found to have positive impact on both task and contextual performance. Better educational level of trainees increases the ability of an individual to understand the content of training program and to implement that effectively after the training exercise. The contextual performance of an employee also gets improved because better education enables an individual to be more socially responsible towards the organization and coworkers. Past experience of trainees in the relevant area was found to have positive impact on the contextual performance only. This implies that experience may not be a consideration while choosing employees for training program that is focused on resultant task performance, however, it results in better candidates when contextual performance is to be targeted. In terms of managerial implications, the findings of study can guide managers to focus on important elements of a training program and personal characteristics of employees to optimize the company's' investment in the costly exercise of training. Considering these factors can positively enhance the required dimension of task or contextual performance as a result from this costly investment as well as to stay competitive with their industry counterparts.

The findings may be limited to the size and selection of sample from banking industry in a specific geographic area. Similarly, additional factors of both training program as well as trainees' characteristics can be brought in for future research in this direction.

\section{Acknowledgements}

This study was supported by JSPSKAKENHI Grant Number 24530500.

\section{References}

Abugre, J. B., \& Adebola, K. (2015). An examination of training and development of middle level managers in emerging economies: Evidence from financial institutions in Ghana. International Journal of Organizational Analysis, 23(4), 545-563. http://dx.doi.org/10.1108/IJOA-10-2011-0521

Aguinis, H., \& Kraiger, K. (2009). Benefits of training and development for individuals and teams, organizations, and society. Annual Review of Psychology, 60, 451-474. http://dx.doi.org/10.1146/annurev.psych.60.110707.163505 
Alliger, G. M., Tamnenbaum, S. I., Bennett Jr, W., Traver, H., \& Shotland, A. (1998). A meta-analysis of the relations among training criteria. Executive Consulting Group Inc Slingerlands Ny.

Aragon-Sanchez, A., Barba-Aragón, I., \& Sanz-Valle, R. (2003). Effects of training on business results1. The International Journal of Human Resource Management, 14(6), 956-980. http://dx.doi.org/10.1080/0958519032000106164

Arthur Jr, W., Bennett Jr, W., Edens, P. S., \& Bell, S. T. (2003). Effectiveness of training in organizations: A meta-analysis of design and evaluation features. Journal of Applied Psychology, 88(2), 234. http://dx.doi.org/10.1037/0021-9010.88.2.234

Artis, A. B., \& Harris, E. G. (2007). Self-directed learning and sales force performance: An integrated framework. Journal of Personal Selling \& Sales Management, 27(1), 9-24. http://dx.doi.org/10.2753/PSS0885-3134270101

Attia, A. M., Honeycutt Jr, E. D., \& Leach, M. P. (2005). A three-stage model for assessing and improving sales force training and development. Journal of Personal Selling \& Sales Management, 25(3), 253-268.

Barrett, A., \& O'Connell, P. J. (2001). Does training generally work? The returns to in-company training. Industrial \& labor relations review, 54(3), 647-662. http://dx.doi.org/10.1177/001979390105400307

Barrett, A., Bergin, A., \& Kelly, E. (2011). Estimating the impact of immigration on wages in Ireland. The Economic and Social Review, 42(1), 1-26.

Barron, J. M., Berger, M. C., \& Black, D. A. (1999). Do workers pay for on-the-job training? Journal of Human Resources, 235-252. http://dx.doi.org/10.2307/146344

Conway, J. M. (1999). Distinguishing contextual performance from task performance for managerial jobs. Journal of applied Psychology, 84(1), 3. http://dx.doi.org/10.1037/0021-9010.84.1.3

Cron, W. L., Marshall, G. W., Singh, J., Spiro, R. L., \& Sujan, H. (2005). Salesperson selection, training, and development: Trends, implications, and research opportunities. Journal of Personal Selling \& Sales Management, 25(2), 123-136.

Georgiadis, A., \& Pitelis, C. N. (2014). The Impact of Employees 'and Managers' Training on the Performance of Small-and Medium-Sized Enterprises: Evidence from a Randomized Natural Experiment in the UK Service Sector. British Journal of Industrial Relations. http://dx.doi.org/10.1111/bjir.12094

Hughey, A. W., \& Mussnug, K. J. (1997). Designing effective employee training programmes. Training for Quality, 5(2), 52-57. http://dx.doi.org/10.1108/09684879710167638

Ibrahim, M. E. (2004). Measuring training effectiveness. Journal of Management Research, 4(3), 147.

J van Zolingen, S., Streumer, J. N., De Jong, R., \& R van der Klink, M. (2000). Implementing on-the-job training: Critical success factors. International Journal of Training and Development, 4(3), 208-216. http://dx.doi.org/10.1111/1468-2419.00108

Katz, E., \& Ziderman, A. (1990). Investment in general training: The role of information and labour mobility. The Economic Journal, 1147-1158. http://dx.doi.org/10.2307/2233964

Kessler, A. S., \& Lülfesmann, C. (2006). The Theory of Human Capital Revisited: On the Interaction of General and Specific Investments. The Economic Journal, 116(514), 903-923. http://dx.doi.org/10.1111/j.1468-0297.2006.01116.x

Kraiger, K., McLinden, D., \& Casper, W. J. (2004). Collaborative planning for training impact. Human Resource Management, 43(4), 337-351. http://dx.doi.org/10.1002/hrm.20028

Krebs, T., Kuhn, M., \& Wright, M. L. (2011). Human capital risk, contract enforcement, and the macroeconomy (No. w17714). National Bureau of Economic Research. http://dx.doi.org/10.3386/w17714

Laberge, M., Vézina, N., Calvet, B., Lévesque, S., \& Vézina-Nadon, L. (2012). Supervision of apprentices in semiskilled trades: Program stipulations and workplace realities. Relations Industrielles/Industrial Relations, 67(2), 199-221. http://dx.doi.org/10.7202/1009084ar

Lechner, M. (1999). Earnings and employment effects of continuous gff-the-job training in east germany after $\begin{array}{llllll}\text { unification. Journal of Business \& Economic Statistics, 17(1), } & \text { 74-90. }\end{array}$ http://dx.doi.org/10.1080/07350015.1999.10524798

Lee, G. J. (2015). Training match and mismatch as a driver of key employee behaviours. Human Resource Management Journal. http://dx.doi.org/10.1111/1748-8583.12069 
Loewenstein, M. A., \& Spletzer, J. R. (1999). General and specific training: Evidence and implications. Journal of Human Resources, 710-733. http://dx.doi.org/10.2307/146414

Madera, J. M., Neal, J. A., \& Dawson, M. (2011). A strategy for diversity training focusing on empathy in the workplace. Journal of Hospitality \& Tourism Research, 35(4), 469-487. http://dx.doi.org/10.1177/1096348010382240

Mafi, S. L. (2001). Planned on-the-job managerial training. Advances in Developing Human Resources, 3(4), 488-495. http://dx.doi.org/10.1177/15234220122238418

Mathieu, J. E., Tannenbaum, S. I., \& Salas, E. (1992). Influences of individual and situational characteristics on measures of training effectiveness. Academy of Management Journal, 35(4), 828-847. http://dx.doi.org/10.2307/256317

Matsuo, M. (2014). Instructional skills for on-the-job training and experiential learning: An empirical study of Japanese firms. International Journal of Training and Development, 18(4), 225-240. http://dx.doi.org/10.1111/ijtd.12035

Mohammed, S., Mathieu, J. E., \& Bart'Bartlett, A. L. (2002). Technical-administrative task performance, leadership task performance, and contextual performance: Considering the influence of team- and task-related composition variables. Journal of Organizational Behavior, 23(7), 795-814. http://dx.doi.org/10.1002/job.169

Morikawa, M. (2015). Postgraduate Education and Labor Market Outcomes: An Empirical Analysis Using Micro Data from Japan. Industrial Relations: A Journal of Economy and Society, 54(3), 499-520. http://dx.doi.org/10.1111/irel.12100

Murthy, N. N., Challagalla, G. N., Vincent, L. H., \& Shervani, T. A. (2008). The impact of simulation training on call center agent performance: A field-based investigation. Management Science, 54(2), 384-399. http://dx.doi.org/10.1287/mnsc. 1070.0818

Salas, E., Wildman, J. L., \& Piccolo, R. F. (2009). Using simulation-based training to enhance management education. Academy of Management Learning \& Education, 8(4), 559-573. http://dx.doi.org/10.5465/AMLE.2009.47785474

Sharma, H. (2014). Importance and performance of managerial training in Indian companies-an empirical study. Journal of Management Development, 33(2), 75-89. http://dx.doi.org/10.1108/JMD-11-2013-0144

Warr, P., \& Bunce, D. (1995). Trainee characteristics and the outcomes of open learning. Personnel Psychology, 48(2), 347-375. http://dx.doi.org/10.1111/j.1744-6570.1995.tb01761.x

Wexley, K. N. (1984). Personnel training. Annual Review of Psychology, 35(1), 519-551. http://dx.doi.org/10.1146/annurev.ps.35.020184.002511

Wexley, K. N., Latham, G. P., Kettering, M., Rivaldo, O. F., Christensen, J., \& FAO, R. I. (1991). Developing and training human resources in organizations (No. C10 25). Department of Agriculture, Washington, DC (EUA). Office of International Cooperation and Development. AID, Washington, DC (EUA). Bureau for Science and Technology.

\section{Copyrights}

Copyright for this article is retained by the author(s), with first publication rights granted to the journal.

This is an open-access article distributed under the terms and conditions of the Creative Commons Attribution license (http://creativecommons.org/licenses/by/3.0/). 